\title{
Broadening Student Learning Experiences via a Novel Cross-Disciplinary Art and Anatomy Education Program - A Case Study
}

\author{
Caroline J. Speed ${ }^{1}$, Adina Kleiner ${ }^{2} \&$ Janet O. Macaulay $^{1}$ \\ ${ }^{1}$ Department of Biochemistry and Molecular Biology, Faculty of Medicine, Nursing and Health Sciences, Monash \\ University, Melbourne, Australia \\ ${ }^{2}$ Department of Anatomy and Developmental Biology, Faculty of Medicine, Nursing and Health Sciences, Monash \\ University, Melbourne, Australia \\ Correspondence: Dr Caroline J. Speed, Department of Biochemistry and Molecular Biology, Monash University, \\ Clayton, 3800, Melbourne, Australia. Tel: 61-3-9905-3799 E-mail: caroline.speed@monash.edu
}

Received: December 10, 2014

Accepted: December 19, 2014

Online Published: December 22, 2014

doi:10.5430/ijhe.v4n1p86

URL: http://dx.doi.org/10.5430/ijhe.v4n1p86

\begin{abstract}
This study explored student learning and engagement in a novel cross-disciplinary education program, in particular whether medical students learning experiences can be enhanced through interaction and exchange of knowledge with students of varying disciplines. The program, entitled AnaRtomy, studies the historical relationship between art and anatomy. A cohort of medical, physiotherapy and fine arts students from Monash University, Australia completed the three week AnaRtomy program in Italy. The benefits of cross-disciplinary learning were substantial as students from different courses learned from each other and gained new perspectives into art and anatomy. The AnaRtomy program supports cross-disciplinary learning and successfully enhances student engagement and learning experiences giving students the opportunity to study abroad and learn through experience.
\end{abstract}

Keywords: Student engagement, Learning experiences, Cross-disciplinary learning

\section{Introduction}

\subsection{Integration of art in medical education}

There has historically been a close connection between medicine and art and this partnership has endured for centuries. Many principles and methods of art education are evident in medical education, such as life drawing and anatomical illustration of the human body (Macnaughton, 2009). In recent years, many medical schools have moved away from cadaver dissection as the main method of teaching human anatomy (Hanna \& Tang, 2005; Turney, 2007). Newer approaches in clinical anatomy teaching involve using multi-media programs to digitally explore anatomical features ('An@tomedia', 2002) as well as life drawing and body painting anatomical features on living models (McMenamin, 2008). The value of incorporating art when learning clinical skills in medical education has been investigated in a number of studies (Elder, Tobias, Lucero-Criswell, \& Goldenhar, 2006; Kirklin, Duncan, McBride, Hunt, \& Griffin, 2007; McMenamin, 2008; Moore, Lowe, Lawrence, \& Borchers, 2011; Naghshineh et al., 2008; Naug, Colson, \& Donner, 2011; Schaff, Isken, \& Tager, 2011; Shapiro, Rucker, \& Beck, 2006). One study has examined the potential learning benefits for medical students involved in an interdisciplinary drawing module (Lyon, Letschka, Ainsworth, \& Haq, 2013). In this study, third year medical students undertook a drawing module on the human body in conjunction with third year arts students. The study indicated that through engagement with students from the arts discipline and the development of creative drawing skills there may be potential learning benefits for medical students. The study of Howell, Gaies, and Saint (2013) created a program within the Michigan Medical School that used a wide range of arts to enhance medical students' abilities to provide clinical care (Howell, Gaies, \& Saint, 2013).

\subsection{Broadening learning experiences in medical education}

Medical curricula can incorporate an excess of theory-based learning at the expense of hands-on experiential learning, particularly in the early years of the degree which often focuses on underpinning basic sciences content knowledge. There is a need to broaden the students learning experiences and encourage cross-disciplinary exchange of knowledge, which is often not encountered by medical students in the early years of their degree. By providing students with opportunities to undertake experiential learning abroad, students can benefit academically, socially and 
culturally (Dolby, 2007; Hanson, 2010). This paper introduces the AnaRtomy program which encompasses a cross-disciplinary approach to learning art and anatomy. It is expected that medical students' learning experiences can be enhanced through interaction and exchange of knowledge with students of varying disciplines in an engaging international environment.

\section{Background}

\subsection{The AnaRtomy program}

The AnaRtomy education program was a collaborative initiative between Monash University Faculty of Medicine, Nursing and Health Sciences and the Faculty of Art and Design. The three week educational program was developed for art and anatomy students and based in Prato, Italy at the Monash Prato Centre. One of the aims of the Monash Prato Centre is to 'develop and expand the opportunities for Monash and other Australian students to study overseas' (Monash University Guide to Undergraduate Courses 2012, http://www.topuniversities.com/sites/qs.topuni/files/413_1333020773_14.pdf). The AnaRtomy program provided students with opportunities to explore the historical relationship between art and anatomy. A range of learning experiences were embedded into the program incorporating art history and anatomy lectures, visits to museums that focused on anatomy and/or art, allocated studio days involving life drawing, drawing on site at museums and anatomical specimen collections, field trips and independent study time (Figure 1).

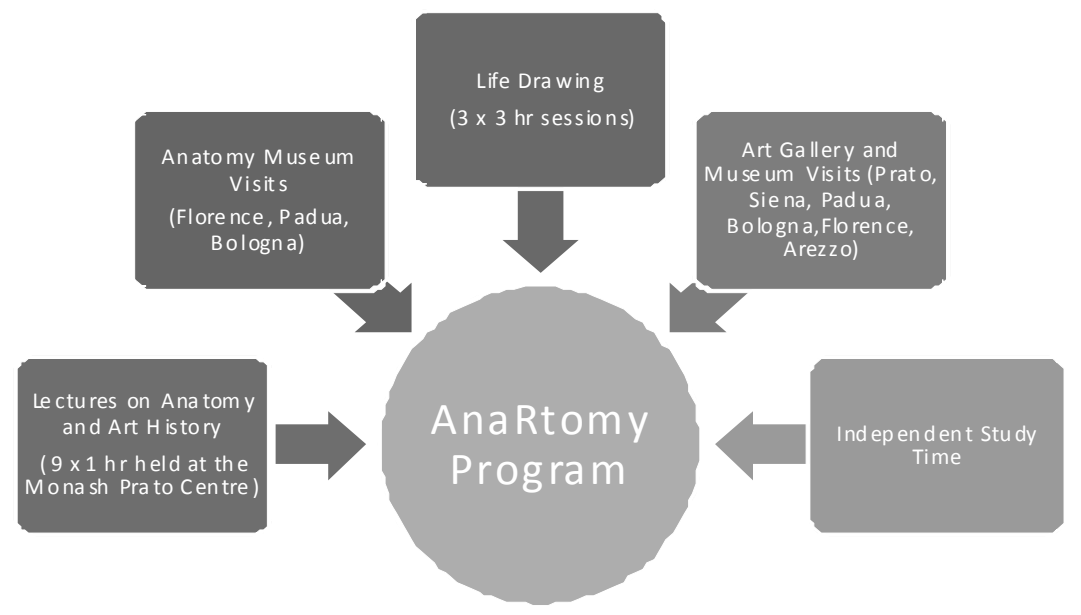

Figure 1. AnaRtomy Program

\subsection{Selection of students}

The program was advertised to the Monash University medical (301 students in year two), physiotherapy (61 students in year four) and fine arts (17 students in year two) student cohorts and expressions of interested were accepted. Students were selected for participation in the AnaRtomy program according to the following selection criteria:

- demonstration of an interest in art and art history (selection was not based on ability in art)

- foundational knowledge of anatomy and an interest in the history of anatomy

- $\quad$ illustration of an interest in exploring the relationship between art and anatomy

- interactions with other students and staff

- $\quad$ academic achievement

Six medical, three physiotherapy and sixteen fine arts students participated in the AnaRtomy program. The gender distribution was medicine: five females and one male; physiotherapy: three females and fine arts: thirteen females and three males.

Students were able to apply to Monash University for funding to support their travel and living expenses through the Monash Study Abroad program (http://monash.edu/study-abroad/). This did not cover the full cost of the program and travel expenses, hence students were required to partially finance the program themselves. 
2.3 Aim of AnaRtomy: Provide a cultural experience where students can immerse themselves in Italian art and the history of anatomy.

\subsection{AnaRtomy Learning Objectives:}

On completion of the AnaRtomy program, students should be able to:

1. Demonstrate an understanding of the application of art to anatomy.

2. Demonstrate an understanding of the application of anatomy to art.

3. Illustrate artistic appreciation, knowledge and skills by constructing a poster/report.

4. Work effectively with students across different disciplines and different cultures.

The AnaRtomy program ran for four weeks (June/July), outside of semester time which incorporated the mid-year vacation, with students spending three weeks studying in Italy and one week in Australia finalising projects. Three experts from Monash University: an anatomist (lecturer in anatomy and qualified physiotherapist), an artist (qualified artist and lecturer in fine arts) and an art historian (professor and lecturer in fine arts) led the AnaRtomy program.

Participation in the AnaRtomy program contributed to Monash University students' final grades with the weighting dependent on the course in which they were enrolled.

Second year medical students: $5 \%$ of the years mark.

Second year fine arts students: $12.5 \%$ of the years mark.

Fourth year physiotherapy students: $7.5 \%$ of the years mark.

\section{Methodology}

\subsection{Data Collection}

After completion of the AnaRtomy program the Monash University students who participated in the program were invited to participate in an evaluation study. A survey was designed to evaluate whether the AnaRtomy program was a valuable educational learning experience for the students enrolled in courses of various disciplines (medicine, physiotherapy and fine arts). The survey specifically evaluated the Monash AnaRtomy program in terms of meeting the learning objectives, the impact on student engagement and the broadening of student learning experiences. The survey also collected information relating to the demographics of the AnaRtomy participants, their prior knowledge of art, anatomy and art history, experiences and opinions of the AnaRtomy program.

The survey was delivered as a paper based survey, was voluntary and anonymous. The survey incorporated both open-ended and closed questions using a five-point Likert scale (five $=$ strongly agree, one $=$ strongly disagree). The open ended questions included a request to reflect on the experience of the AnaRtomy program. The evaluation study received human ethics approval through the Monash University Human Research Ethics Committee.

\section{Results and Discussion}

\subsection{Demographic data}

Of the students who opted to participate in the survey, sixty seven percent were medical students, seventeen percent were physiotherapy students and seventeen percent were fine arts students. The majority of respondents (sixty seven percent) were under 19 years of age. All respondents were studying full time and thirty three percent spoke Italian which aided them in communications whilst in Italy.

\subsection{Cross-disciplinary student interactions}

Analysis of student responses showed that sixty seven percent strongly agreed and thirty three percent agreed that the AnaRtomy program enabled interactions with students enrolled in other courses and that the cross-disciplinary interactions between the medical, physiotherapy and fine arts students allowed for the sharing of knowledge and enhanced learning (Figure 2). 


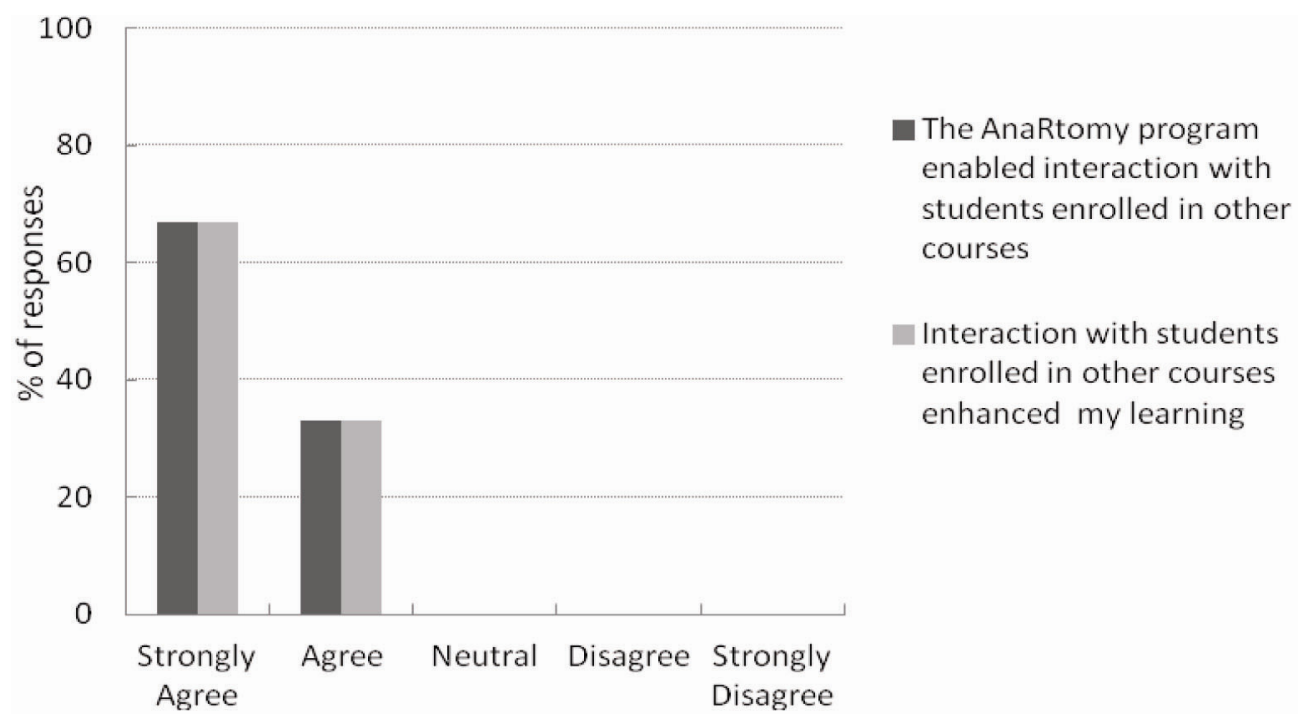

Figure 2. Cross-disciplinary student interactions enhance learning

By introducing a cross-disciplinary approach to learning, the medical, physiotherapy and fine arts disciplines all benefited from each other. The learning experiences of the students were enhanced through interactions with students of varying disciplines. The medical students were assisted by the fine arts students with their anatomical drawings and in return the medical and physiotherapy students assisted the fine arts students with their understanding of anatomy. As a result, the medical and physiotherapy students enhanced their anatomical drawing skills while the fine arts students learned anatomical nomenclature. Thus, AnaRtomy learning objective four 'Work effectively with students across different disciplines and different cultures' was achieved by the AnaRtomy program.

The written responses to the open-ended question 'What did you gain by interacting with students from other courses?' (below) provides further evidence that the cross- disciplinary student interactions provided by the AnaRtomy program enhanced learning.

Question: What did you gain by interacting with students from other courses?

Responses:

Sharing knowledge and helping each other with different aspects of learning (Year two medical student A)

Learning to collaborate with people with different skills and backgrounds (Year two medical student B)

I felt the creative side of my brain being whirred up again. This is something that we don't get to do often in a course outside of Medicine so it was an absolute pleasure in learning about a new perspective (Year two medical student C)

Insight into other courses....I have learnt so much outside the medicine world that we live in at uni (Year two medical student D)

Different perspectives of art and anatomy....We benefited from our interaction by developing our academic knowledge, developing skills in teamwork and communication, and subsequently augmenting skills required in our future professional careers (Year four physiotherapy student A)

Making new friends and learning from each other (Year two fine arts student A)

These responses highlight that a cross-disciplinary approach to learning can broaden students learning experiences.

In addition to the students perspective the evaluation of the program included feedback from the expert artist involved in the AnaRtomy program. The artist (Monash University lecturer in fine arts) delivered the art lectures and workshops in Prato and also accompanied the students on the excursions but was not involved in the overall design of the AnaRtomy program. She provided the following insight of the AnaRtomy program from the teacher's perspective.

Exploring the history of art and anatomy outside the context of standard classroom teaching, allowed the students not only to explore a new culture, but placed their studies into a broader historical and cross-disciplinary context, and fostered mutual understanding and integration of students from different fields of study. The interaction presented as an embodiment of the ideas and concepts explored through the AnaRtomy program, focusing on the shared 
histories and connections between art and anatomy, and provided an important dimension to the program. (AnaRtomy teacher)

\subsection{Learning experiences and student engagement with the AnaRtomy program}

The entire cohort of students from varying disciplines found the AnaRtomy program to be highly engaging. This finding was based on verbal and written feedback given by the students to the AnaRtomy teaching staff. Attending field excursions to historical museums and galleries combined with lectures on art history and anatomy and life drawing sessions gave all students exposure to learning experiences that cannot be captured in a University setting. The students were so highly engaged that groups of students from different disciplines were often observed by staff to be engrossed in discussions. Medical and arts students for example bonded over their appreciation of anatomical paintings or sculptures and assisted each other with anatomical nomenclature and sketches of body parts.

To complete their assessment for the AnaRtomy program, the medical students were required to work in groups of three and select a person (anatomist/artist) that existed between the periods of 1400-1900. Within their groups, the medical students researched and submitted a written report (and bibliography) that included a biography of the anatomist/artist and the techniques, teaching methods and philosophies of the selected individual. The medical students consulted the arts and physiotherapy students when completing their projects and the arts students in particular were of great assistance to the medical students with their interpretation of artistic drawing styles and philosophies of the anatomist/artist. The cross-disciplinary learning and engagement with the AnaRtomy program ensured that all medical students completed their assessment tasks to a very high standard (high distinction). The medical students gained knowledge and advanced anatomical drawing skills that will be of great benefit to their future careers.

The medical students where asked to reflect on their experiences of the AnaRtomy program. Below are some reflections:

The AnaRtomy program has the potential to offer a unique educational experience. There may exist opportunities for the student to learn what essentially cannot be taught, especially in a classroom environment. There is a delicate balance, however, that must be maintained in terms of supervisor guidance. Too little, and there is a risk of students lacking direction and failing to take full advantage of the program. Too much, and there is a risk of turning the program into an 'everyday', didactic university tutorial, and losing the sense of discovery altogether. The AnaRtomy program has the potential to become a powerful educational tool for many students (Year two medical student A)

This program has given me an opportunity to explore medicine in a completely different way. I was able to build on my understanding of the history of medicine and the development of anatomy, whilst also having the chance to collaborate with a number of students outside of medicine (Year two medical student B)

I feel as if overall this has been a very valuable experience, it has allowed us to extend our knowledge and pursue our other interests. I think it is vital for medical students to be given opportunities to exercise their other skills within an academic context, and this course allowed us to do so (Year two medical student C)

The AnaRtomy program was an amazing experience for me and one which I hold many fond memories of. The students on the study tour were fantastic, I think a large part of the reason I enjoyed the trip so much was because I was surrounded by so many remarkable people (Year two medical student D)

The reflections highlight the potential learning benefits that can be obtained by participating in cross-disciplinary education. Learning through experience and through collaboration with students from other disciplines has the potential to improve student engagement and learning outcomes. The study performed by Lyon et al. (2013) also highlighted the deeper learning and engagement that medical students obtained through collaborative anatomical drawing with students from an arts discipline.

\section{Conclusion}

The AnaRtomy program is very specialised and relies heavily on the involvement of specialised, dedicated staff with particular interests in art, art history and anatomy and a commitment to the program. If staffing changes, it may be difficult to maintain the program. Also of consideration are equity issues as the program is only available to a small cohort of students and does rely on a financial contribution from the students. However the program is not a core component of the courses but an option for those students with an interest in the combined disciplines of art, art history and anatomy.

The integration of the AnaRtomy education program into the medical curriculum for selected students was successful in enhancing student engagement and learning experiences. The benefits of cross-disciplinary learning were 
substantial as students from different courses learned from each other and gained new perspectives into art and anatomy. The advanced anatomical knowledge and drawing skills gained by the medical students will set them in good stead for the remainder of their medical degree and future careers. AnaRtomy is a unique educational program for medical students, giving students the opportunity to study abroad and learn through experience.

\section{Conflict of Interest}

The authors declare that they have no conflict of interest.

\section{References}

An@tomedia ${ }^{\mathrm{TM}}$ (2002). Department of Anatomy and Cell Biology. The University of Melbourne, Melbourne, Australia. URL: http://www.anatomedia.com/ (accessed August 8, 2013)

Dolby, N. (2007). Reflections on nation: American undergraduates and education abroad. Journal of Studies in International Education 11: 141-156. http://dx.doi.org/10.1177/1028315306291944

Elder N.C., Tobias B., Lucero-Criswell A., \& L. Goldenhar. (2006). The art of observation: impact of a family medicine and art museum partnership on student education. Family Medicine 38: 393-398.

Hanna, S.J., \& T. Tang. (2005). Reduced undergraduate medical science teaching is detrimental for basic surgical training. Clinical Anatomy 18: 465-466. http://dx.doi.org/10.1002/ca.20122

Hanson, L. (2010). Global citizenship, global health, and the internationalization of curriculum: A study of transformative potential. Journal of Studies in International Education 14: 70-88. http://dx.doi.org/10.1177/1028315308323207

Howell, J.D., Gaies, E., \& S. Saint. (2013). Using a novel medical arts program to integrate the art and science of medicine. International Journal of Medical Education 4:198-199. http://dx.doi.org/10.5116/ijme.523d.a0cf

http://monash.edu/study-abroad/

Kirklin, D., Duncan, J., McBride, S., Hunt, S., \& M. Griffin. (2007). A cluster design controlled trial of arts-based observational skills training in primary care. Medical Education 41: 395-401. http://dx.doi.org/10.1111/j.1365-2929.2007.02711.x

Lyon, P., Letschka, P., Ainsworth, T., \& I. Haq. (2013). An exploratory study of the potential learning benefits for medical students in collaborative drawing: creativity, reflection and 'critical looking'. BMC Medical Education 13: 86. http://dx.doi.org/10.1186/1472-6920-13-86

Macnaughton, J. (2009). Flesh revealed: medicine, art and anatomy. In The Body and the Arts. Palgrave Macmillan: 72-86.

McMenamin, PG. (2008). Body painting as a tool in clinical anatomy teaching. Anatomical Sciences Education 1: 139-144. http://dx.doi.org/10.1002/ase.32

Monash University Guide to Undergraduate Courses 2012, http://www.topuniversities.com/sites/qs.topuni/files/413_1333020773_14.pdf

Moore, C.M., Lowe, C., Lawrence, J., \& P. Borchers. (2011). Developing observational skills and knowledge of anatomical relationship in an art and anatomy workshop using plastinated specimens. Anatomical Sciences Education 4, no. 5: 294-301. http://dx.doi.org/10.1002/ase.244

Naghshineh, M.D., Hafler, J.P., Miller, A.R., Blanco, M.A., Lipsitz, S.R., Dubroff, R.P., Khoshbin, S., \& J.T. Katz. (2008). Formal art observation training improves medical students' visual diagnosis skills. Journal of General Internal Medicine 23, no. 7: 991-997. http://dx.doi.org/10.1007/s11606-008-0667-0

Naug, H.L., Colson, N.J., \& D.G. Donner. (2011). Promoting metacognition in first year anatomy laboratories using plasticine modeling and drawing activities: a pilot study of the 'Blank Page' technique. Anatomical Sciences Education 4, no. 4: 231-234. http://dx.doi.org/10.1002/ase.228

Schaff, P.B., Isken, S. \& R.M. Tager. (2011). From contemporary art to core clinical skills: observation, interpretation and meaning-making in a complex environment. Academic Medicine 86, no. 10: 1272-1276. http://dx.doi.org/10.1097/ACM.0b013e31822c161d

Shapiro, J., Rucker, L. \& J. Beck. (2006). Training the clinical eye and mind: using the arts to develop medical students' observational and pattern recognition skills. Medical Education 40: 263-268. http://dx.doi.org/10.1111/j.1365-2929.2006.02389.x

Turney B.W. (2007). Anatomy in a modern medical curriculum. Annals of The Royal College of Surgeons of England 89: 104-107. http://dx.doi.org/10.1308/003588407X168244 